\title{
In Conversation with Sir Denis Hill
}

The following is the second part of Sidney Bloch's interview with Sir Denis Hill. Part I appeared in the May Bulletin.

SB I suppose many people would see the chairmanship of the Institute of Psychiatry as the crowning glory of your career.

DH You've got it wrong-because I think that what you're saying is that the Professor of Psychiatry is not only chairman, but also Director of the Institute. The Institute has no Director and has never had one. Nor is the Professor of Psychiatry chairman in any sense. It so happens that he is made chairman of several important committees, but he is hardly primus inter pares with other heads of departments. The Institute is a series of independent departments, of which the Departments of Psychiatry and Psychology are much the largest. The Professor of Psychiatry is given special responsibilities in relation to clinical teaching and to the work of the hospital, and although from time to time he has to assume the role of leadership, he can only do so if he can carry his colleagues along with him.

My predecessor, Aubrey Lewis, was a $\cdot$ man of outstanding personality and intellect, and since he more or less built up the Institute from nothing, and all members of the staff were men and women whom he had educated himself, it was one large family. The atmosphere was one of awe, reverence and a great deal of affection for Aubrey at the time I succeeded him. When I was appointed he wrote to me and said, 'I hope your reign will be as happy as mine'-which astonished me tremendously! In fact the role of the Professor of Psychiatry at the Institute changed dramatically after he left. The first thing that happened was that we moved into a large, brand-new building and the Department of Psychiatry and other departments expanded enormously. The Department of Psychiatry became very large indeed by the time I left. It had nine Professors, twenty-two Senior Lecturers, several Lecturers and well over a hundred research workers. The Seniors were mostly full-time people, but there were many conferred titles. It was, I suppose, one of the largest departments in the world.

When I went to the Institute, although I knew a lot about the place and a lot of people there (I had run a department in the Institute for years, and had been a consultant on the Maudsley staff), things had changed. A striking thing was that a series of brilliant young men had been prepared-if that is the correct word-by specialist training, many of them with MRC Research Fellowships, and a lot of experience, to fill roles in specialist subjects of psychiatry. All I had to do was to open the doors for them, to let them grow up-and this is what I did. I didn't have to exert myself particularly hard. There they were, ready to fly off, to be independent, to create their own departments. One of the things I had to do was to get money for buildings and for the endowment of Chairs. I worked hard on that and we got a lot of money from all sorts of bodies, including, surprisingly enough, the DHSS. The Board of Governors were extremely generous-they endowed Michael Rutter's Chair of Child Psychiatry. Other voluntary organizations endowed other Chairs. And then a whole series of brilliant young men were given personal Readerships by the University and then personal Chairs. Many Chairs at the Institute are personal, and end when the individuals retire. Nevertheless, the result has been that we kept some of the leading people in different subspecialties. They might have been tempted to go off elsewhere had they not been given a place in the sun. That was part of my policy, to keep people of the highest quality in particular branches of our subject.

SB Some critics argue that there's been too much sun in just one area of London and not enough elsewhere and that this has been to the detriment of British psychiatry as a whole.

DH I'm well aware of this. In fact when I was at the Middlesex I talked about what I called the hegemony of the Maudsley in a report which I made to the Medical Research Council. One of the functions, though, of the Maudsley Institute, if I can call it that, has always been to breed the future teachers and research workers in psychiatry, and in all its branches. That applies also to psychology. I know that various people have said just what you have said, and have been critical of the fact that several distinguished people were unwilling to go off elsewhere when invited again and again, and that we didn't push them out. We had no means of doing so even if we had wished to, and we did not wish to. However, seven years ago, when we were considering the future of the Maudsley and the Institute, I asked several bodies including the then Dean of the College and the DHSS: 'Should the Institute and Maudsley change its policy?' Everybody said no.

Over the years I didn't think that there were many departments in psychiatry, certainly none in London, that were yet sufficiently well established and viable for the production of the future teachers and research workers of psychiatry. In a small department, there is always the danger that its Professor is appointed to a national post, and therefore cannot be in his department except one or two days a week. So long as a department depends upon one man only-this applies also to MRC and Research Units-it is not viable. 
Only when you have a critical mass of academics who are independent and sufficiently senior can you afford to push off from the shore.

SB Do you think that the splendour of the Maudsley has retarded the development of these critical masses elsewhere?

DH I don't agree with this at all. Look around the country and see how many senior academics now filling Chairs are Maudsley products. The Maudsley provided the first generation of academic psychiatrists of quality. No other place in the UK, with the possible exception of Edinburgh, could have done this. It's changing now, because some provincial departments are producing their own people.

SB Should the Maudsley role now change?

DH This is happening already. The question of how it changes is a matter for debate. Should it become a research institute or a highly specialized centre devoted to certain developing subjects? Should it cease to provide general psychiatric training and only give advanced training or advanced clinical research? These are the sorts of questions that have been asked. I think that, so far as the Maudsley will change it won't change from inside but will be moulded by outside events.

SB Another criticism I have heard levelled against the notion of a powerful Institute is the danger of a stereotyped profession. You have already mentioned the many Chairs occupied by products of the Maudsley. So Maudsleyites are scattered around the country and perhaps the profession becomes limited by a specific vision of how psychiatry should be practised and researched. Is this a problem?

DH Yes. I've not the slightest doubt that different ideas and approaches, and people with various forms of expertise will progressively appear in academic psychiatry. I'm very impressed by developments, for example, in social psychology. What the Maudsley did with its first generation of academic chicks was to create something that was scientifically acceptable. It produced people of whom Aubrey Lewis would have approved, namely they had enquiring minds, curiosity, scepticism, and they developed a capacity for evaluating evidence critically. They were not outstanding clinicians but they were far and away better than anything in the field of academic psychiatry that had been produced in the UK before. Now you can say they were a bit stereotyped, but so would be the sort of research physician who came out of the Royal Postgraduate Medical School.

SB Do you think that this was the only possible course of events? Because the side-effect, I suppose, may have been to retard psychiatry in some ways.

DH Difficult to say how retarding. If the effect has been to prevent people with other potentially fertile approaches from coming in-social psychologists, sociologists, people with a new look at dynamic psychotherapy and social therapy-then in that sense it must have been retarding, but I suspect that one will not be able to answer that question until after a decade or two.

SB You mentioned people with 'enquiring minds', with clinicals skills possibly being of lesser priority. I wonder also about therapeutic skills. In my own experience at the Maudsley we spent considerable time gaining clinical information, whereas the actual therapeutic effort was not as keen as I've seen it elsewhere.

DH There has always seemed to be, unfortunately, an antithesis between the strengths of an academic in psychiatry and the strengths he has for therapeutic skills, psychotherapeutic skills in particular. But there is an antithesis. The two ways of thinking do not appear to be compatible. And I would be the last person to defend my academic brethren on the grounds that they are good psychotherapists. I know they are not. In fact many of them are, for practical purposes, not therapists at all and don't wish to be. They don't wish to involve themselves very much with patients, which is a very sad thing, but there it is. When I was at the Maudsley I did my best to try to marry the different sides of psychiatry without the usual onset of contempt or mutual hostility. It is surprising, really, how mutual hostility persists in this country, despite every effort one makes to stop it.

I put my faith in youth. It's the young who seem to me to understand. And the young - the registrars in training now at the Maudsley-seemed to me when I left to have a tolerant attitude to academics. The difficulty is that in their recognition that senior academics are often not very good at helping patients psychotherapeutically, they themselves tended to be slightly contemptuous of academic psychiatry. This is damaging because they lose out all round.

SB You mention that you have tried to bring together those who are therapeutically inclined and those who are research inclined. It seems to me that one of the strengths that you have shown throughout your career is what I might call the 'integrationist' position. How you have managed to maintain such a wide range of interests beats me-neuropsychiatry, forensic psychiatry, psychotherapy, education in psychiatry.

DH I haven't positively sought out anything very much. I've been led by my nose. It's almost accident that I got into neuropsychiatry. It's accident that I met Grey Walter. It's accident that I did EEGs on murderers, which got me into forensic psychiatry. It's not accident, I suppose, that as a medical student I was interested in psychiatry. A temperamental thing I suppose. It's not accident that I was interested in psychotherapy because Bill Hubert, an outstanding psychotherapist at St Thomas', was a great inspiration. But a lot of it has been accident.

SB Stumbling into something is perhaps the most exciting way of doing it. But you have maintained your integra- 
tionist approach. Your perspective is wide, altogether an unusual position?

DH Yes, that's right. I've found only a few people of my own generation who have my sort of perspective. There have been people in the States, of course. One thing I regard as a great sin, if $I$ believe in sin at all, is to hold a total ideology. I think that in psychiatry, in medicine as a whole, if you have a total ideology you're just no good. If you believe that everything that an individual does is determined by his unconscious, you're just no good. If you believe that everything a person does is a result of external stimulation of a psychological nature, you're just no good. If you believe that schizophrenia is due to an abnormal metabolite you may be right, but if you think there's nothing else to do until you've found it, you're no good.

SB Well then, are there a lot of no-good people around?

DH I'm defending my attitude: that the holding of a total ideology is one of the most destructive things that can happen to any man or woman, and I hate it. But what I do say is that all the different approaches we see in psychiatry-some of them more scientific than others-have something to offer, and in particular cases may have all to offer. I don't think we can afford to neglect any of them.

SB You talk of some approaches being more scientific than others. It's a great slogan that for psychiatry to be an academic subject we must be scientifically-minded, and the current concept of science is that of Karl Popper. Any new paradigm doesn't get much support. Are you saying that that position is short-sighted or blinkered?

DH I think that this word 'science' is grossly misrepresented and misused. If you're talking about science in a Popperian sense, then we are referring to the nature of proof and that's all. I think science is knowledge, and the only characteristic about scientific thinking and scientific activity, is that the individual who engages in it must stick to the truth. And that's really all that matters, although truth can be elusive, difficult to be sure about. Science is the collection of knowledge, and initially it's a collection of facts. Whether a fact is a fact is always arguable, but if you stick to the truth as far as you can see it, that's all that you can do. If you're going in for experimental science, which is another thing altogether, then you have to use the Popperian criteria of refutability. So for one lot of people to say another lot of people are not scientific is rubbish. They must be specific and say in what way, in what respects this or that is not scientific.

SB I suppose some people would accuse you of being a wishy-washy eclectic.

DH I daresay they would.

SB Can you tolerate that?

DH Well, there you are. This is another thing that you have to do. You have to tolerate criticism and even hostility, but it depends what your job is - what you are trying to do. If you hold a position of responsibility and authority, the chief thing is to look after people. You have to take the good with the bad, and you have to take even the hostility of the people you're responsible for without actually swiping them.

SB Could we end on a personal note. You've been involved with so many different activities throughout your career. How have you managed?

DH A great number were routine. You just work on day after day. I have, I assure you, given up things which I found unpleasant or which I disliked, or had no interest in. For example, I served for only a year on the Personnel Selection Board of the Air Ministry. I was quite unsuited to it. I had nothing really to contribute to it. And that's not the only one I resigned from. A lot of committee work I did as a duty - because that was part of the job. One of the most difficult things I faced at the Institute was to be able to give my mind to a whole series of different people with different problemsresearch problems, personal problems, other problems-to switch every half hour was difficult. The worst thing of all was the extent to which it cut down any sort of personal creative work.

SB What about cutting down on personal life-the pursuit of hobbies or pastimes?

DH I'm actually a dull person artistically. I have become so, because when I was adolescent and a bit later I actually did some painting and sculpture. I like music, and I'm always happy to go to an art gallery if I have time. I was in New York about four years ago and my wife made me go to the Metropolitan (where the Monet exhibition was on) and to the Museum of Modern Art, which was almost next door to our hotel. But I believe that if she hadn't been there I would not have found the time. I have no interest in sport. I come from a background of a farming family which was very interested in sport, all country sports. As a boy I rode and shot and did all that sort of thing, but I lost all interest in it. I couldn't tell you the name of a single footballer, cricketer or tennis-player. The theatre? Well, even when I lived in central London we didn't go very often; it was rather that my wife used to make me go. There are few modern playwrights I like. I am fond of Shaw, Ibsen and Chekhov. I have some country interests which I have to look after-but I'm very fond of the country and like being in it. My particular interests are in a sense professional; I'm interested in ideas-biological, psychological, philosophical, and I like reading.

SB How are you spending your retirement?

DH I've written more in the way of papers since I retired two years ago than I did in the previous ten, I think. The GMC takes up a lot of time; I act for the President as 'preliminary screener' for conduct and health. 
When I retired I didn't think I'd have anything to do at all and so when I was offered anything I grabbed it hungrily, and it's all come home to roost this summer. As you know, I had a delightful six weeks as Litchfield Lecturer, living in Merton College and working in the Oxford Psychiatry Department, I have lectured in Edinburgh and Canterbury, I gave the Curran Lecture last year at St George's, I'm giving the Aubrey Lewis Lecture this year-I'm as busy now as I want to be, sometimes more than I want to be.

SB You feared that life would be empty considering that you'd spent so much time pursuing career interests?

DH I did work very hard. I gave up a lot of things on retirement, automatically. But you get used to routine, and when suddenly there's no routine you have to have a different discipline, which I hadn't. After all, I had been in active practice for $\mathbf{4 5}$ years. It was a new life. But it couldn't be better than it is now. A lot of retired people have said to me 'Oh, I'm terribly busy' and I've never believed them, but I do believe them now.

SB Forty-five years-it's a long span. You have a rather unique perspective because psychiatry has changed so much over that period. What impression do you have of those changes?

DH I symphathized with what Felix Post wrote about his career (British Journal of Psychiatry, 1978, 133, 83-86). It struck a chord with me because his experience was very much mine. When I first entered psychiatry there was practically nothing one could do for the psychotic and severely depressed patients except give them dangerous sedative drugs that were bad for their kidneys or their hearts. And you went on month after month, year after year, and some got better and some didn't. There was nothing else you could do. There was great optimism about psychotherapy in those days, in the early 1930s. Psychotherapy seemed to be the potential answer if one could only dissect out the essential elements of what to do. Then new techniques arrived-convulsive therapy, insulin coma therapy, leucotomy. It did seem as if there were a new range of treatments that would help people. Certainly, many schizophrenics improved with insulin coma therapy. I always thought they got better because they were slightly drunk as they came out of their coma and the nurses used to put their arms round them and form relationships with them.
ECT was very impressive when we first used it. For patients with depression of later life it seemed a miracle, because one had seen them suffer for two, three, four years in the most frightful mental pain, the most terrible agitation, and only then would they recover. Of course in the 1950s, the major tranquillizers and the antidepressants completely changed psychiatric practice. The prognosis in terms of duration of illness was changed out of all recognition. Illnesses that usually lasted months and sometimes years now lasted weeks or less.

I see a great opening up of opportunities for the relief of the mentally ill-and if I have any fear-one shouldn't really fear it-but if I have any fear it is that psychiatrists will become unnecessary, superfluous. As far as the skills go to give antidepressant drugs and tranquillizers, any good physician can do this. As far as treating a lot of the behavioural quirks such as obsessions and compulsions there's little that I can do as a psychiatrist, little that I believe a neurosurgeon can do. little a drug can do-but the behaviourists can. So it's possible that Eysenck may be right, that the role of the psychiatrist will disappear because a large part of the work will be taken over by physicians and neurologists and the rest will be taken over by psychologists. I don't believe that really to be true, but I think some of our work might be taken over by social workers.

I don't believe that psychiatrists have any specific solutions for the anguishes and the depressions and the sorrows of this world. I don't believe we should try to solve them, because we can't. The only thing we can do is to try to study the theory of human nature, which will then allow us to understand how human nature goes wrong. For example, it's very interesting that someone who can't be depressed is abnormal. It's equally interesting that someone who is so pathologically depressed as to be what we call psychotic is abnormal. It's also equally interesting that everybody who isn't at either end of that spectrum can be depressed and can tolerate it; or if he can't tolerate it he does something to get help. The tolerance of unpleasant emotions is something we should be concerned with and we should look at the theory of these phenomena. But as practising doctors we may have a very different role in the future.

Sir Denis Hill (1913-1982)

Many readers will have learnt the sad news of Sir Denis's death on 5 May. A tribute to him will be published in a later issue. 